нее и Нижнее Поволжье и Заволжье. СПб.: Изд-во А.Ф. Дервиена, 1901. 599 с.

11. Список населенных мест Самарской губернии, составлен в 1900 году секретарем Самарского губернского статистического комитета И.А. Протопоповым / сост. И.А. Протопопов. Самара: Губ. тип., $1900.520 \mathrm{c}$

12. РГИА. Ф. 395. Оп. 1. Д. 916.

13. Костромитинов Г.Н. О сельскохозяйственных опытах в Бузулукском уезде. Самара: тип. Н.К. Реутовского, 1893. 22 с.

14. Постановления Самарского губернского собрания XXXX очередной сессии. Самара, 1906. С. 11-14.

15. Центральный государственный архив Самарской области. Ф. 468. Оп. 1. Д. 916.

16. Шеремеев Е.Е. Самарский «сфинкс» при правительстве Колчака: А.К. Клафтон (1871-1920 гг.) биография на фоне эпохи. Самара: Изд-во Самарского научного центра РАН, 2011. 337 с.
17. Тучи собираются // Голос Самары. 1906. 28 марта.

18. Наумов А.Н. Из уцелевших воспоминаний. 1868-1917. Кн. 2. Нью-Йорк: Изд. А.К. Наумовой и О.А. Кусевицкой, 1955. 584 с.

19. Алексушина Т.Ф. Самарские страницы российского дворянства. Самара, 2013. 536 с.

20. Шеремеев Е.Е. Кадеты Самары на выборах в IV Государственную Думу России // Наука и культура России: мат-лы VIII междунар. науч.-практ. конф., посв. Дню славянской письменности и культуры памяти святых равноапостольных Кирилла и Мефодия. Самара: Самарский государственный университет путей сообщения, 2011. С. 54-57.

21. БД Красноярского общества «Мемориал» [Электронный ресурс] // http://memorial.krsk.ru.

22. БД Жертвы политического террора в СССР [Электронный pecypc] // http://lists.memo.ru/index11.htm.

\title{
SAMARA LANDOWNER AND LIBERAL GEORGY NIKOLAEVICH KOSTROMITINOV
}

(C) 2019

Barinova Ekaterina Petrovna, doctor of historical sciences, professor of Institutional Economy and Economic History Department Samara State University of Economics (Samara, Russian Federation)

Kabytov Pyotr Serafimovich, doctor of historical sciences, professor, head of Russian History Department Kabytova Nadezhda Nikolaevna, doctor of historical sciences, professor of Russian History Department Samara National Research University (Samara, Russian Federation)

Abstract. Based on the analysis of archival documents, periodicals, memoirs the paper reconstructs the biography of an outstanding political figure - a member of the constitutional democratic party, one of the organizers of the provincial branch of the cadet party in the Samara province, deputy of the 1st State Duma G.N. Kostromitinov. The authors have defined stages of his life and work as well as the main directions of his economic activity. The authors also emphasize the importance of G.N. Kostromitinov's participation in the work of Zemstvo institutions. It contributed to the development of his political views and had a significant impact on development of the Samara nobleman as a prominent regional public figure. During the revolutionary events of 1905, he became one of the leaders of the Samara cadets, which led to the election of G.N. Kostromitinov to the 1st State Duma. The authors have recreated the process of the constitutional democratic party branch establishment in the Samara province, G.N. Kostromitinov's place and role in the leadership and activities of the Samara branch of the party of the cadets. The authors have also established his relationships with the provincial leaders A.A. Chemodurov and A.N. Naumov. The paper presents biographical data about G.N. Kostromitinov's son - M.G. Kostromitinov before and after the Great Russian revolution and Civil war, it also considers his tragic death during Stalin's repressions. The results can serve as a basis for further reconstruction of the socio-political portrait of the Russian nobility.

Keywords: Georgy Nikolaevich Kostromitinov; political biography; genealogical data; nobility; territorial activity; liberals; leaders of nobility; Samara province; State Duma; constitutional democratic party; first Russian revolution; political repressions.

УДК 94 (47)

DOI $10.24411 / 2309-4370-2019-12227$

Статья поступила в редакцию 21.07.2018

\section{ЖИВОТНОВОДСТВО УРАЛА В УСЛОВИЯХ ВЕЛИКОЙ ОТЕЧЕСТВЕННОЙ ВОЙНЫ} (C) 2019

Бахтияров Рустам Сулейманович, кандидат исторических наук, преподаватель

Илекский зоотехнический техникум - филиал Оренбургского государственного аграрного университета (с. Илек, Оренбургская область, Российская Федерация)

Федорова Алла Владимировна, доктор исторических наук, профессор, заведующий кафедрой истории и философии

Оренбургский государственный аграрный университет (2. Оренбург, Российская Федерация)

Аннотащия. В статье рассматривается роль животноводства в уральском экономическом районе. Особое внимание уделено периоду Великой Отечественной войны 1941-1945 гг. Статья содержит материалы, характеризующие ситуацию в отрасли в предвоенное время, дает оценку процессам, происходившим в основных сферах животноводства при переходе от единоличного крестьянского способа организации животноводства к промышленным технологиям в конце 30-х годов XX века. При проведении коллективизации на Урале, как и по всей стране, поголовье продуктивных животных понесло большие потери. Только поголовье мелкого 
рогатого скота за 1928-1935 гг. сократилось с 9,1 млн голов до 3 млн голов, т.е. в 3 раза. Осознав пагубность подобной политики, руководство СССР приняло энергичные меры к исправлению ситуации, но в целом к началу Великой Отечественной войны полный переход на новые принципы работы в сельском хозяйстве осуществлен не был. Начавшаяся война повысила роль животноводства Урала в масштабах СССР. Если к началу 1941 г. в хозяйствах региона содержалось от 5,1 до 8,3\% поголовья основных сельскохозяйственных животных страны, то в самые тяжелые 1942-1943 гг. войны этот показатель возрос до 10,8 и даже 18,6\% от всего продуктивного стада СССР. В этот период животноводство региона давало до $15 \%$ всей молочной продукции страны и 13-14\% мяса. Таким образом, труженики животноводства Урала в тяжелейших условиях военного времени смогли спасти основную часть поголовья животных и обеспечить армию, а также оборонную промышленность региона необходимым продовольствием и сырьем.

Ключевые слова: СССР; Урал; Великая Отечественная война; сельское хозяйство; животноводство; поголовье скота; крупный рогатый скот; мелкий рогатый скот; коневодство; свиноводство; племенные совхозы; Курганский госплемрассадник; эвакуация; колхозники; трудовые ресурсы; падеж; корма; трудовые ресурсы.

История уральского экономического района, превратившегося в один из ключевых регионов нашего государства, глубоко изучена. Но в то же время гораздо менее известна роль Урала как крупного сельскохозяйственного района. Наличие собственного развитого сельского хозяйства во многом обеспечило возможность масштабного промышленного роста на Урале. Данное обстоятельство наглядно подтвердилось и в годы Великой Отечественной войны.

Необходимо отметить, что сама возможность промышленного производства без использования продукции сельского хозяйства была в принципе не реализуема. Особое место при этом принадлежит важнейшей сфере аграрного производства - животноводству. Без его продукции в виде сырья и расходных материалов (кожа, шерсть, животный жир, воск и т.д.) не могли работать даже металлургические производства Урала. Отсутствие быстроходного транспорта делали доставку сырья и расходных компонентов из регионов на значительные расстояния делом дорогостоящим и ненадежным.

Для крупных населенных пунктов, возникших при промышленных объектах, в больших количествах требовалось и продовольствие, которое в условиях сурового уральского климата и огромных расстояний в России было крайне сложно доставить в необходимых количествах. Кроме того, промышленное производство требовало и гужевой транспорт: лошадей и волов, которых поставляло сельское хозяйство.

К середине XX века зависимость масштабного промышленного производства от компонентов, поставляемых сельским хозяйством, несколько снизилась, но тем не менее продукцию пчеловодства, например, в середине 40-х гг. использовали до 40 отраслей народного хозяйства СССР [1, л. 23].

Увеличение численности городского населения в регионе в 20-30-х гг. также потребовало дополнительного объема продовольствия. Поэтому в предвоенные годы, помимо пристального внимания к промышленному производству, руководство СССР прилагало значительные усилия и к совершенствованию аграрного производства в регионах уральского экономического района.

В регионе предпринимались энергичные меры к подъему уровня сельского хозяйства в целом и в животноводстве в частности. Особенно это стало актуальным после не совсем оправданных мероприятий в период коллективизации сельского хозяйства, когда по некоторым видам скота, таким как, например, овцы, продуктивное поголовье упало за 5-6 лет к 1934 г. в три раза. В 1928 г. области и республики Урала имели 9,1 млн голов мелкого рогатого скота. К 1934 г. уровень поголовья упал до 3 млн голов и воз- рос до 7,2 млн лишь к 1941 г. [2, с. 233, 241, 250]. Ряд источников данные 1941 г. считают заниженными. Для преодоления этих последствий на Урале, как и по всей стране, создали различные специализированные предприятия и хозяйства, отвечавшие за улучшение работы отрасли.

За короткий срок были созданы племенные совхозы и колхозные племенные фермы. Постепенно вводилось районирование скота согласно природноклиматическим условиям области или республики. Возникли животноводческие тресты, объединившие совхозы одного направления. Появились заготовительные конторы, мясокомбинаты, призванные обеспечить эффективную переработку животноводческой продукции и т.д.

Так, в 1933 г. в Уральской области создали государственный племенной рассадник тагильского скота, а в 1935 г. организовали Курганский госплемрассадник, в котором впоследствии вывели курганскую породу скота. В Чкаловской (Оренбургской) области сотрудники Чкаловского научно-исследовательского института мясомолочного скотоводства под руководством ученого-зоотехника К.А. Акопяна, начиная с середины 30-х гг., активно работали над повышением мясной продуктивности местного скота. В результате они стали соавторами созданной в послевоенный период казахской белоголовой породы. Перечень мероприятий по подъему животноводства, проводимых на Урале в конце 30-х гг., может быть многократно продолжен.

Не все проведенные мероприятия оправдали себя, но они позволили начать постепенный переход животноводства уральского региона от традиционных форм работы к промышленному товарному производству. Хотя, как отмечали ведущие специалисты в области изучения сельского хозяйства Урала, к 1941 г. аграрное производство региона, как и все сельское хозяйство СССР, еще не завершило полное освоение современных технологий. Это отрицательно сказалось на результатах работы в военных условиях [3, с. 65].

Тем не менее к началу 1941 г. в областях и республиках региона имелось до 7,5\% поголовья крупного рогатого скота в СССР; до $8 \%$ поголовья лошадей; $8,3 \%$ овец и коз; 5,1\% от численности продуктивного стада свиней [4, с. 155, 159, 166, 169].

Начавшаяся 22 июня 1941 г. Великая Отечественная война еще в большей степени повысила роль уральского животноводства. Неблагоприятный ход первых месяцев войны привел к тому, что враг занял наиболее развитые в сельскохозяйственном отношении районы СССР. На ней остались десятки миллионов голов скота. Рискуя жизнью, животново- 
Бахтияров Р.С., Федорова А.В.

ды западных районов СССР смогли спасти некоторое количество животных, но это не могло в целом компенсировать потери. Так, только в 1941 г. из 12 млн голов лошадей и 109 млн голов прочего продуктивного поголовья (крупного рогатого скота, овец, свиней), содержавшихся на утраченных территориях, удалось эвакуировать: 2390 тыс. голов крупного рогатого скота, 186 тыс. свиней, 5082 тыс. овец и коз, 818 тыс. лошадей [5, с. 518].

Ю.В. Арутюнян, детально проанализировав происходившие в ходе эвакуации скота процессы, приводит в своем исследовании следующие показатели: из 16500 тыс. довоенного поголовья мелкого и крупного рогатого скота колхозов УССР, БССР и западных районов РСФСР до пунктов размещения дошли только 2212,8 тыс. голов (13,4\%), а к 1 января 1942 г. осталось всего 433,1 тыс. голов или 3\% от довоенного поголовья [6, с. 53].

В результате этого на тыловые районы легла вся нагрузка по обеспечению армии и населения всеми видами продовольствия и сырья. О динамике процессов, происходивших в животноводстве Урала, можно получить представление из нижеприводимых данных [4, с. 155, 159, 166, 169] (табл. 1).

Как видно из данных табл. 1, в самые трудные 1941-1943 гг. роль животноводства Урала в сельском хозяйстве СССР резко возросла. Это произошло во всех сферах продуктивного стада основных сельскохозяйственных животных.

Если в промышленности 1943 г., действительно, стал переломным и там начался устойчивый рост производства основных видов продукции, то в сельском хозяйстве СССР, как показали исследования ведущих ученых-историков в области сельского хозяйства, в 1941-1945 гг. все происходило несколько иначе.

Самым трудным для аграрного производства Coветского Союза в целом и животноводства в частности оказался именно 1943 г., когда хозяйства тыловых районов исчерпали довоенные ресурсы и оказались не в состоянии сдерживать падение производства. Некоторый рост поголовья основных сельскохозяйственных животных (за исключением лошадей) в масштабах страны по итогам 1943 г. связан с тем, что в общем поголовье страны учтены и животные освобожденных от врага районов. Это давало возможность авторам некоторых работ советского периода говорить о переломе в сельском хозяйстве страны в 1943 г., вообще не учитывая специфику статистических показателей.

Тыловые же регионы СССР, в том числе и Урал, смогли остановить падение производства в животноводстве не ранее 1944-1945 гг., о чем наглядно свидетельствуют показатели табл. 1. Также из показателей табл. 1 видно, что наиболее пострадавшей от условий военного времени стала такая важная отрасль, как свиноводство, которая оказалась наиболее уязвимой от трудностей военного времени. К концу 1943 г. в СССР останется только 20\% животных от довоенного поголовья. На Урале эта цифра сократится до $38 \%$ к концу 1944 г.

Данной динамике, происходившей в животноводстве уральского региона, способствовали несколько процессов. К основным из них, безусловно, можно отнести быстрое истощение в годы войны материально-технических и трудовых ресурсов. Так, например, в 1940 г. уральские колхозы собрали 8275,6 тыс. тонн зерновых культур, а в 1943 г. только 2806,7 тыс. тонн, т.е. за 3 года падение составило $77,4 \%$ [4, с. 130$]$. В ряде случаев не хватало не только концентрированных кормов, но и элементарных сена и соломы. По сохранившимся архивным сведениям, в 1942 г. колхозы Чкаловской области смогли засеять кормовыми культурами только 65751 га вместо 247 тыс. га запланированных, или 27\%. При этом нехватка рабочих рук и техники не позволили скосить до 230 тыс. га сенокосов из имевшихся 1065 тыс. га [7, л. 16, 17; 8, л. 75, 108; 9, л. 103]. Нехватка помещений для содержания скота также оказала чрезвычайно неблагоприятное влияние на состояние животноводства в регионах Урала в 1941-1945 гг.

По сведениям курганских исследователей, уже в 1942 г. количество ферм и скотомест в области сократилось на 5-10\%, а в 1943 г. колхозы области имели только $25,9 \%$ типовых помещений для скота, например, в ряде совхозов области из 152 коровников только 11 являлись стандартными $[10$, с. 62, 76]. Летом 1942 г. колхозы Чкаловской области из требовавшихся 1707,4 тыс. мест для скота имели только 1189,3 тыс. [7, л. 14].

Таблица 1 - Поголовье основных сельскохозяйственных животных на Урале в годы Великой Отечественной войны в 1941-1945 гг., тыс. голов на конец года

\begin{tabular}{|c|c|c|c|c|c|c|}
\hline Территория & 1940 г. & $1941 г$. & 1942 г. & 1943 г. & 1944 г. & 1945 г. \\
\hline \multicolumn{7}{|c|}{ Численность крупного рогатого скота во всех категориях хозяйств } \\
\hline Урал & 4091,9 & 3752,1 & 3874,8 & 3525,7 & 3621,6 & 3963,4 \\
\hline $\mathrm{CCCP}$ & 54517,0 & 31405,0 & 28392,0 & 33943,0 & 44189,0 & 47569,0 \\
\hline Урал, \% к СССР & 7,5 & 11,9 & 13,6 & 10,4 & 8,2 & 8,3 \\
\hline \multicolumn{7}{|c|}{ Численность поголовья лошадей во всех категориях хозяйств } \\
\hline Урал & 1668,7 & 1465,9 & 1368,8 & 1093,3 & 904,8 & 934,9 \\
\hline $\mathrm{CCCP}$ & 20998,0 & 10033,0 & 8147,0 & 7703,0 & 9869,0 & 10720,0 \\
\hline Урал, \% к СССР & 7,9 & 14,6 & 16,8 & 14,2 & 9,2 & 8,7 \\
\hline \multicolumn{7}{|c|}{ Численность мелкого рогатого скота во всех категориях хозяйств } \\
\hline Урал & 7572,8 & 6296,2 & 6076,6 & 5143,2 & 4820,2 & 4936,0 \\
\hline $\mathrm{CCCP}$ & 91587,0 & 70602,0 & 61814,0 & 63305,0 & 70246,0 & 70025,0 \\
\hline Урал, \% к СССР & 8,3 & 8,9 & 10,8 & 8,1 & 6,9 & 7,0 \\
\hline \multicolumn{7}{|c|}{ Численность поголовья свиней во всех категориях хозяйств } \\
\hline Урал & 1415,1 & 1277,9 & 1123,7 & 601,8 & 536,5 & 634,5 \\
\hline $\mathrm{CCCP}$ & 27517,0 & 8167,0 & 6030,0 & 5607,0 & 8817,0 & 10557,0 \\
\hline Урал, \% к СССР & 5,1 & 15,6 & 18,6 & 10,7 & 6,1 & 6,0 \\
\hline
\end{tabular}


Особо необходимо остановиться на такой важной для сельского хозяйства военного времени проблеме, как нехватка рабочих рук. Если в промышленности и на транспорте в годы войны широко применялась практика бронирования ценных специалистов, то в сельском хозяйстве указанная практика встречалась гораздо реже. В основном бронировались кадры механизаторов.

В работе Ю.В. Арутюняна приводится факт, что еще до войны нагрузка на одного колхозника на Урале была в 2 раза выше, чем в европейской части СССР. Если после начала войны в среднем по СССР численность трудоспособных колхозников уменьшилась на 37,2\%, то на Урале - на 45\% [6, с. 75]. О наличии трудовых ресурсов в хозяйствах уральского региона можно получить представление из следующих цифр: [11, с. 541, 542] (табл. 2).

Как видно из приведенных показателей, максимальное сокращение трудовых ресурсов к 1944 г. составило $40 \%$, что несколько отличается от показателей, приведенных выше, но в целом не противоречит факту массового сокращения трудоспособных.

Перечень неблагоприятных факторов, оказавших влияние на животноводство региона, может быть многократно продолжен. Данная тема за последние десятилетия стала предметом исследования не одной диссертации, и касаться подробно всех аспектов проблемы в рамках статьи было бы нецелесообразным. Очевидно одно, что, несмотря на все трудности военного времени, работники животноводства Урала проявили самые высокие морально-деловые качества и смогли в годы войны обеспечить армию и рабочих важнейших оборонных заводов продовольствием.

В качестве кормов животноводы региона начали использовать ранее широко не применявшиеся в качестве корма лебеду, крапиву, сапропель (донные отложения водоемов) с их предварительной обработкой по методикам, разработанным учеными. Вместо мужчин на фермы пришли женщины, старики, дети, которые, не жалея себя, совершили свой подвиг, выполнив в неимоверных лишениях и страданиях возложенную на них работу.
О масштабах производства основных видов животноводческой продукции в хозяйствах уральского экономического района можно получить представление из нижеуказанных показателей: [4, с. 182, 199, 205] (табл. 3).

Из приведенных данных видно, что хозяйства Урала в военные годы по некоторым позициям увеличили свою долю в общесоюзном производстве до более чем 2-х раз и в самые тяжелые годы войны давали стране до 15\% молочных продуктов и $13-14 \%$ мяса. Многие хозяйства при этом смогли добиться выдающихся даже по стандартам мирного времени показателей. Для примера можно привести колхоз «Победитель» Алапаевского района Свердловской области, где доярка М.Р. Дунаева надаивала от каждой коровы по 3750 литров молока в год [12, с. 231]. Этот показатель превышал средние надои, имевшие место в развитых государствах в 60-е годы [13, с. 31].

Кроме непосредственно животноводческой продукции для оборонных заводов, хозяйства региона выделили тысячи лошадей, которые использовались в строительстве предприятий, заготовке топлива и доставке выпущенной продукции до станций погрузки.

Так, архивные сведения сохранили информацию о том, что только в 1941 г. 26 государственных предприятий и организаций Чкаловской области получили из колхозов лошадей для своих нужд. К примеру, особому строительству НКВД направили 295 голов, предприятию «Орскметаллургстрой» - 455 голов, спецзаводам оборонной промышленности - 250 голов и т.д. [9, л. $102 ; 14$, л. $77 ; 15$, л. 12]. В начале 1943 г. на заводе № 707 в Челябинской (с февраля 1943 г. Курганской) области имелось 46 лошадей, директор завода А.К. Генкин просил выделить заводу еще не менее 100 голов, без которых не могла осуществляться нормальная работа предприятия, выпускавшего боеприпасы [16, л. 2-12]. Надо сказать, что при этом десятки тысяч лошадей из хозяйств региона были отправлены в действующую армию.

Таблица 2 - Наличие трудовых ресурсов в колхозах Урала, тыс. чел. на конец года

\begin{tabular}{|l|c|c|c|c|c|c|}
\hline \multicolumn{1}{|c|}{ Категории работников } & 1940 г. & 1941 г. & 1942 г. & 1943 г. & 1944 г. & 1945 г. \\
\hline Всего трудоспособных & 2429,2 & 1895,5 & 1727,2 & 1545,2 & 1457,8 & 1586,0 \\
\hline Трудоспособных мужчин & 1178,3 & 601,2 & 387,0 & 286,4 & 272,4 & 402,6 \\
\hline
\end{tabular}

Таблица 3 - Производство основных видов животноводческой продукции на Урале в годы Великой Отечественной войны

\begin{tabular}{|c|c|c|c|c|c|c|}
\hline & 1940 г. & 1941 г. & 1942 г. & 1943 г. & 1944 г. & 1945 г. \\
\hline \multicolumn{7}{|c|}{ Производство мяса основных видов во всех категориях хозяйств, тыс. тонн } \\
\hline Урал & 245,6 & 257,2 & 187,4 & 194,7 & 146,1 & 162,5 \\
\hline CCCP & 3053,3 & 1964,8 & 1482,1 & 1425,7 & 1576,7 & 2062,2 \\
\hline Урал, \% к СССР & 8,0 & 13,1 & 12,6 & 13,7 & 9,3 & 7,9 \\
\hline \multicolumn{7}{|c|}{ Производство молока во всех категориях хозяйств, тыс. тонн } \\
\hline Урал & 2236,4 & 2332,2 & 2352,9 & 2420,2 & 2396,3 & 2607,5 \\
\hline CCCP & 33640,0 & 25495,0 & 15762,0 & 16391,0 & 22044,0 & 26428,0 \\
\hline Урал, \% к СССР & 6,6 & 9,1 & 14,9 & 14,8 & 10,9 & 9,9 \\
\hline \multicolumn{7}{|c|}{ Производство шерсти во всех категориях хозяйств, тонны } \\
\hline Урал & 12873 & 12324 & 10811 & 9309 & 7223 & 8205 \\
\hline $\mathrm{CCCP}$ & 161000 & 161000 & 125000 & 100236 & 102835 & 110600 \\
\hline Урал, \% к СССР & 8,0 & 7,7 & 8,6 & 9,3 & 7,0 & 7,4 \\
\hline
\end{tabular}


По неполным данным, только за 1942 г. колхозы Удмуртии сдали в Красную Армию 5854 лошади [17]. 71 тысячу лошадей дали фронту хозяйства Башкирской АССР, не менее 31 тыс. животных направили на фронт животноводы Чкаловской (Оренбургской) области и 13,5 тыс. Челябинской области [18; 19, л. 196; 20, л. 91].

Таким образом, наличие собственного сельского хозяйства и особенно животноводческой отрасли помогло уральскому экономическому району в условиях военного времени решить проблемы обеспечения населения региона продовольствием и сырьем, а также дать необходимые ресурсы для вооруженных сил.

\section{Список литературы:}

1. Государственный архив Оренбургской области (ГАОО). Ф. Р-1014. ОП. 7. Д. 513.

2. Филатов В.В. Уральское село, 1927-1941 гг.: динамика и темпы развития животноводства. Магнитогорск: ГОУ ВПО «МТТУ», 2006. 264 с.

3. Корнилов Г.Е. Уральская деревня в период Великой Отечественной войны (1941-1945 гг.). Свердловск: Изд-во Урал. гос. ун-та, 1990. 223 с.

4. Мотревич В.П. Сельское хозяйство Урала в показателях статистики (1941-1950). Екатеринбург: Наука. Урал. отд-ние, 1993. 306 с.

5. История Великой Отечественной войны Советского Союза 1941-1945: в 6 т. / ред. комис. П.Н. Поспелов, В.А. Андреев, А.И. Антонов, И.Х. Баграмян, П.А. Белов. М.: Воениздат, 1963. Т. 2. 679 с.

6. Арутюнян Ю.В. Советское крестьянство в годы Великой Отечественной войны. 2-е изд., доп. М.: Наука, 1970. 466 с.

\section{ANIMAL HUSBANDRY OF THE URALS REGIONS IN THE CONDITIONS OF THE GREAT PATRIOTIC WAR}

(C) 2019 2003. $608 \mathrm{c}$.
7. ГАОО. Ф. Р-1014. Оп. 2. Д. 206.

8. ГАОО. Ф. Р-1014. Оп. 2. Д. 262.

9. ГАОО. Ф. Р-1014. Оп. 7. Д. 313.

10. Кодинцев А.Я., Подливалов В.В., Федченко М.Н. Экономика Южного Зауралья периода Великой Отечественной войны и первых послевоенных лет (1941-1953). Курган: Изд-во Курган. гос. ун-та, 2004. $160 \mathrm{c}$.

11. Хисамутдинова Р.Р. Аграрная политика Советского государства на Урале после окончания Великой Отечественной войны (июнь 1945 - март 1953 гг.). Оренбург: Изд-во Оренб. гос. пед. ун-та,

12. Урал - фронту / под ред. А.В. Митрофановой. М.: Экономика, 1985. 344 с.

13. Холманов А.М., Осадчая О.Ю. Скотоводство и производство молока в мире // Зоотехния. 2009. № 8. С. 31 .

14. ГАОО. Ф. Р-2727. ОП. 1. Д. 4.

15. ГАОО. Ф. Р-2727. ОП. 1. Д. 5.

16. Государственный архив Курганской области. Ф. Р-434. Оп. 2. Д. 1.

17. Великая отечественная война в Удмуртии. В труде, как в бою [Электронный ресурс] // http://izarticle.ru/voinaur.html.

18. Башкортостан в годы Великой Отечественной войны [Электронный pecypc] // http://yapatriotrb.ru/ about-us/chitalnya/243-bashkortostan-v-godi-velikoyotechestvennoy-voyni.html.

19. ГАОО. Ф. Р-1014. Оп. 7. Д. 314.

20. Объединенный государственный архив Челябинской области. Ф. Р-1491. Оп. 1. Д. 91.

\title{
2019
}

\author{
Bakhtiyarov Rustam Suleimanovich, candidate of historical sciences, lecturer \\ Ilek Zootechnical College - branch of Orenburg State Agrarian University \\ (Ilek, Orenburg Region, Russian Federation) \\ Fedorova Alla Vladimirovna, doctor of historical sciences, professor, \\ head of History and Philosophy Department \\ Orenburg State Agrarian University (Orenburg, Russian Federation)
}

\begin{abstract}
This paper deals with the role of animal husbandry in the history of the Ural economic region as the most important economic base of Russia, especially during the great Patriotic war of 1941-1945. The study contains materials characterizing the situation in the industry in the prewar period, estimates the processes taking place in the main areas of animal husbandry in the transition from the sole of the peasant way of organizing production to industrial technologies in the late 30s of XX century. During the collectivization in the Urals, as throughout the country, the number of productive animals suffered heavy losses. Only the number of small cattle in 1928-1935 decreased from 9,1 million heads to 3 million heads, i.e. 3 times. Realizing the harmfulness of such a policy, the Soviet leadership took vigorous measures to correct the situation. They allowed to significantly correct the situation, but in general by the beginning of the great Patriotic war, the full transition to the new principles of work in agriculture hadn't been carried out. When the war broke out the role of animal husbandry in the Urals in the USSR increased. At the beginning of 1941 the farms of the region contained from 5,1 to $8,3 \%$ of the population of the main agricultural animals of the country, then during the most difficult years of 1942-1943 this figure increased to 10,8 and even 18,6\% of the total productive herd of the USSR. During this period, the livestock of the region gave up to $15 \%$ of all dairy products of the country and $13-14 \%$ of meat. Thus, the workers of animal husbandry of the Urals in the most difficult conditions of war time were able to save the bulk of the livestock and provide the army and defense industry of the region with the necessary food and raw materials.

Keywords: USSR; Ural; Great Patriotic war; animal husbandry; branch; cattle; small cattle; horses; horse breeding; mobilization; case; forages; labor resources; productive herd; agriculture; collective farm; livestock; food; production; victory.
\end{abstract}

